\title{
Gender Differences in Pulmonary Function, Respiratory Symptoms, and Macrophage Proteomics among HIV-Infected Smokers
}

\author{
Shiva D. Rahmanian, ${ }^{1}$ Karen L. Wood, ${ }^{1,2}$ Shili Lin, ${ }^{3}$ Mark A. King, ${ }^{4}$ April Horne, \\ Shangbin Yang, ${ }^{5}$ Haifeng M. Wu, ${ }^{5}$ and Philip T. Diaz ${ }^{1}$ \\ ${ }^{1}$ Division of Pulmonary, Critical Care, and Sleep Medicine, Department of Medicine, The Ohio State University Medical Center, \\ Columbus, OH, USA \\ ${ }^{2} 201$ Davis Heart and Lung Institute, 473 West 12th Avenue, Columbus, OH 43210, USA \\ ${ }^{3}$ Department of Statistics, The Ohio State University, Columbus, OH 43210, USA \\ ${ }^{4}$ Department of Radiology, The Ohio State University Medical Center, Columbus, OH 43210, USA \\ ${ }^{5}$ Department of Pathology, The Ohio State University Medical Center, Columbus, OH 43210, USA
}

Correspondence should be addressed to Karen L. Wood; karen.wood@osumc.edu

Received 1 December 2013; Accepted 23 January 2014; Published 4 March 2014

Academic Editors: P. Borger and G. Miserocchi

Copyright (C) 2014 Shiva D. Rahmanian et al. This is an open access article distributed under the Creative Commons Attribution License, which permits unrestricted use, distribution, and reproduction in any medium, provided the original work is properly cited.

Background. HIV-infected subjects have an increased incidence of pulmonary emphysema. There are known gender differences in COPD phenotypic expression and diagnosis, but this is not well characterized in lung disease related to HIV. We analyzed a group at risk for the development of COPD (HIV-infected smokers) to determine gender differences in pulmonary symptoms, pulmonary function tests, and HRCT appearances. Methods. This was a cross-sectional, baseline analysis of a prospective study performed between 2006 and 2010. We performed symptomatic, pulmonary function, and computed tomography assessments in 243 HIVinfected smokers. In a subset bronchoalveolar lavage was performed with proteomic analysis of their alveolar macrophages. Results. The majority of the participants were male 213 (87.6\%). There was significantly higher percentage of cough and phlegm production in males. There was also a lower FEV1 and a higher RV in males than females. Proteomic analysis revealed 29 proteins with at least a 2 -fold higher expression in males and 13 identified proteins that were higher in females. Conclusions. In this group of HIV-infected smokers, airway symptoms and pulmonary function test abnormalities were higher in men than women. These gender differences may be due to differential expression of certain proteins in this group.

\section{Introduction}

The prevalence of chronic obstructive pulmonary disease (COPD) is increasing dramatically in women. In fact, COPD now kills more women than breast and lung cancer combined [1] and the number of new cases of COPD is increasing three times as fast in women annually as compared to men [2]. Data suggests that there are differences in the presentation and phenotypic expression of COPD in women compared to men [3], While women may be more susceptible to early onset COPD, there appears to be a gender bias in the diagnosis of
COPD, with women less likely to be diagnosed than men with similar symptoms $[4,5]$.

Human immunodeficiency virus (HIV) has emerged as an independent risk factor for COPD in smokers, as data in the pre- and postantiretroviral (ART) era demonstrate increased susceptibility to cigarette smoke and a high percentage develop abnormalities in lung function, including loss of diffusing capacity and irreversible air-flow obstruction $[6,7]$. As ART has transformed HIV into a chronic disease, noninfectious pulmonary comorbidities are assuming greater importance for this population [8]. Whether cigarette 
smoking affects HIV-infected women differently than men has not been systematically studied.

The purpose of the current study was to compare respiratory symptoms, lung function, and results of high resolution computed tomography (HRCT) scanning among HIV-infected women and men. While previous studies have defined phenotypic differences between men and women in advanced COPD in the general population $[4,5]$, we were interested in studying an at risk group of smokers at an earlier disease stage. In addition, we examined alveolar macrophage proteomics in a subgroup of males and females. We wished to determine whether differences in protein expression existed between the two groups and whether such differences could provide mechanistic insight into observed symptomatic and physiologic differences.

\section{Materials and Methods}

This was a cross-sectional, baseline analysis of a prospective study performed between 2006 and 2010. The study involved the longitudinal assessment of the pulmonary status of HIVinfected subjects $(n=315)$ and included symptomatic, pulmonary function, and computed tomography assessment. In addition, a subset of agreeable subjects underwent bronchoalveolar lavage followed with proteomic analysis of their alveolar macrophages. The study was approved by the Ohio State University institutional review board (Biomedical Sciences IRB number 2005H0197) and all subjects signed informed consent. For the purposes of this analysis, only participants who had a history of cigarette smoking were included $(n=243)$.

2.1. Respiratory Symptoms. All subjects answered questions related to the presence or absence of respiratory symptoms, specifically, shortness of breath, cough, phlegm production, and wheezing.

2.2. Pulmonary Function Studies. All participants underwent complete pulmonary function testing, including spirometry, as well as measurement of lung volumes and carbon monoxide diffusing capacity according to American Thoracic Society guidelines. Predicted equations for spirometry were those of Goldman [9], lung volumes Crapo [10], and diffusing capacity Miller [11].

2.3. Computed Tomography of the Chest. All subjects underwent HRCT (high resolution computed tomography) of the chest. Scans were performed on a Siemens multislice CT scanner (16-slice, 20-slice open CT, or 64-slice), without IV contrast. Inspiratory and expiratory images were performed. All scans were read by an experienced chest radiologist. The presence or absence of emphysema (bullae, thin-walled cystic spaces, or abnormal decreases in attenuation accompanied by vascular disruption) was recorded, as was the presence of bronchial dilatation, bronchial wall thickening, and air trapping as previously described [12].
2.4. Alveolar Macrophage (AM) Proteomics. To examine alveolar macrophage proteomics, we matched 6 female subjects with 6 male subjects of similar age, smoking history, and use of ART. Briefly, a bronchoalveolar lavage (BAL) in the right middle lobe was performed to obtain a lavage sample of approximately $50 \mathrm{~mL}$ for the isolation of AMs [13]. After obtaining BAL, an initial centrifugation was performed to spin down AMs. AM purity in each cell preparation was evaluated by light microscopic examination of diff-quick cytospins to ensure at least $90 \%$ purity. After preparation of AMs, a small aliquot of AM cells was suspended in RIPA buffer for protein concentration measurement using BCA protein assay [14]. Afterwards, AMs obtained from each participant were lysed at a density of $3-5 \times 10^{6} \mathrm{cells} / \mathrm{mL}$ in $2 \mathrm{D}$ gel cell lysis buffer [13] and frozen at $-80^{\circ} \mathrm{C}$ for $2 \mathrm{D}$ gel proteomic analysis performed in batches.

For first dimension electrophoresis, $100 \mu \mathrm{L}$ cell lysates ( $\sim 2 \mathrm{mg}$ cellular proteins) were mixed with $400 \mathrm{~mL}$ rehydration buffer and spun at $14,000 \mathrm{~g}$, at $4^{\circ} \mathrm{C}$ for 10 minutes. Four hundred fifty $\mu \mathrm{L}$ of the supernatant was then subjected to first D electrophoresis overnight on an Amersham IPGphor using premade $24 \mathrm{~cm}$ IPG strips. Following first D electrophoresis, the strip was equilibrated in a buffer containing for $10 \mathrm{~min}$. at room temperature. This is followed by a second equilibration for $10 \mathrm{~min}$. Second dimension electrophoresis was run on a 20 $\times 24 \mathrm{~cm}$ SDS-PAGE on an Amersham Dalt II, a large format $(20 \times 24 \mathrm{~cm}) 2 \mathrm{D}$ gel system. Under this condition, a total of approximately $1,100-1,500$ protein spots were detected and analyzed in each AM sample.

After 2D electrophoresis, the gels were fixed and stained with SyproRuby fluorescence dye according to manufacturer's protocol. Gel images were captured on a Typhoon 9200 laser scanner (Amersham) that offers high resolution and quantification of protein spots. Protein quantification on all 2D gels was performed using ImageMaster 2D software (Nonlinear Dynamics) [13, 15, 16]. Proteins demonstrating significant and reproducible differences between male and female HIV smokers were subjected to protein identity determination using tandem mass spectrometry at OSU's Proteomic Shared Core Facility.

2.5. Statistical Analysis. The prevalence of respiratory symptoms, findings on high resolution chest $\mathrm{CT}$, and pulmonary function testing were analyzed using linear/logistic models with sex, age, pack-years smoking history, viral load, BMI, and IV drug use as covariates. Because of skewness in the data, log transformation was performed on pack-years smoking history, residual volume, BMI, and viral load before model fitting.

\section{Results}

3.1. Participants. Table 1 demonstrates the baseline characteristics of the study population. The sex distribution and demographics of the population were similar to that of the HIV demographics of Central Ohio 30 females (12.3\%) and 213 males $(87.6 \%)$. The mean age of the participants was 44.3 with 57.6\% Caucasians, $40.7 \%$ African Americans, and 1.7\% 
TABLE 1: Baseline demographics of the study participants.

\begin{tabular}{lc}
\hline Demographics & All subjects \\
\hline Subject number & 243 \\
Male number (\%) & $213(87.6 \%)$ \\
Female number (\%) & $30(12.3 \%)$ \\
Age, mean (std dev) & $44.3(8.4)$ \\
BMI, mean (std dev) & $26.98(8.35)$ \\
Race & \\
$\quad$ Caucasian (\%) & 40.7 \\
$\quad$ African American (\%) & 57.6 \\
$\quad$ Other (\%) & 1.7 \\
IV drug use number (\%) & $43(17.7 \%)$ \\
Current smokers number (\%) & $157(64.6 \%)$ \\
$\quad$ Pack years, mean (std dev) & $19 \pm 20.1$ \\
CD4 count, mean (std dev) & $473.85 \pm 284.80$ \\
Viral load, mean (std dev) & $36552.43 \pm 118323.6$ \\
\hline
\end{tabular}

other. The average pack-year history of the group was 19; $63 \%$ of females and $65 \%$ of males were current smokers. The average viral load was 36,552 with an average CD4 count of 474.

\subsection{Respiratory Symptoms, Pulmonary Function Testing, and} Radiographic Imaging. Table 2 demonstrates clinical pulmonary findings among the subjects according to participant gender. Males had a significantly higher prevalence of cough (72.8\% versus $51.7 \%(P=0.0015))$ and phlegm production (71.2\% versus $51.7 \%(P=0.025))$ compared to females. There was no statistically significant differences between males and females with regard to shortness of breath $(32.4 \%$ males versus $44.8 \%$ females $(P=0.87))$ and wheezing $(49.8 \%$ males versus $55.2 \%$ females $(P=0.89))$.

A comparison of the HRCT findings did not reveal any differences regarding the prevalence of emphysema, bronchial dilatation, or bronchial wall thickening. Although there was no statistically significant difference in the prevalence of air trapping, there was a trend towards significance (29.1\% males versus $22.2 \%$ females $(P=0.083)$ ).

Based on pulmonary function testing, males had a lower percent predicted forced expiratory volume in one second (FEV1). The average FEV1 percent predicted was $91.4 \%$ in males versus $97.3 \%$ in females $(P=0.0086)$. There was also a higher prevalence of air trapping as measured by the residual volume (RV) in males compared to females with an average $\mathrm{RV}$ of $115.1 \%$ in males compared to $99.41 \%$ in females $(P=$ $0.0496)$. While there was no significant difference between males and females with regard to diffusion impairment, both groups exhibited diffusion impairment with a mean diffusing capacity for carbon monoxide (DLCO) of less than $80 \%$ predicted in both groups $(79.9 \%$ in males and $75.5 \%$ in females).

3.3. Proteomic Analysis. Table 3 demonstrates the subset of subjects that underwent BAL and proteomic analysis. There were 6 men and 6 women who were matched for HAART therapy, smoking status and pack years, age and race. Tables 4 and 5 demonstrate results of 2D gel alveolar macrophage proteomic analysis between men and women. Sixty-five proteins were identified that were at least twofold greater in men of which 29 were identified (Table 4). Thirty-eight proteins were identified that were at least twofold greater in women of which 13 were identified (Table 5).

\section{Discussion}

The current study indicates that in a population of HIVinfected smokers there are gender differences in pulmonary function and respiratory symptoms. Males have an increased prevalence of cough and phlegm production, as well as lower $\%$ of predicted FEV1 and a higher \% of predicted RV. HRCT scanning demonstrated a trend to increased air trapping. Of note, the degree of diffusion impairment was similar between the two sexes as was the degree of emphysema on chest CT. The overall findings suggest among the HIV-infected population, male smokers may be more likely to develop early airways dysfunction than female smokers.

Studies examining gender differences among individuals with COPD in the general population suggest that women may be more susceptible to the effects of cigarette smoke. In a study by Silverman and colleagues [5] gender differences in severe early-onset COPD were studied by examining 84 earlyonset COPD subjects and 348 of their first degree relatives. They found a similar level of airflow obstruction in male and female subjects; however, females had a tendency to smoke less. In first degree relatives, when analyzing current or exsmokers, female first degree relatives had a significantly lower FEV1/FVC ratio, significantly greater bronchodilator response, and more likely to have an FEV1\% predicted less than $40 \%$. It has been suggested that women may have a specific phenotype of COPD, that is, more airway disease predominant, whereas men tend to have more of an emphysematous phenotype. Based on a retrospective review of 1438 patients with a diagnosis of COPD, spirometric evidence of airflow obstruction, and CT scan data, a significantly greater proportion of women had airway disease [3]. Sex differences may exist on computed tomography as well, as it appears that men may have more emphysema on CT than women for the same degree of obstruction [17].

Our study is somewhat different from other studies that have examined established, advanced COPD; instead, we studied a group of at risk smokers finding that airway symptoms and loss of FEV1 appear to be more common in men. While airways disease seemed to be less affected in our population of women, diffusion impairment was prominent. Interestingly other studies on the non-HIV infected population have suggested that early in the presentation of COPD, women may have less airway disease, but greater diffusion impairment [18]. Furthermore, phlegm production has been seen to be more prominent in men with early COPD and respiratory symptoms better correlate with abnormal spirometry in men compared to women [19]. The different phenotypic expression of COPD at an early stage may in part explain why women are diagnosed at a later stage. Processes affecting gas exchange may be more clinically subtle and may 
TABLE 2: Comparison of sex differences in respiratory symptoms, chest CT findings, and pulmonary function testing.

\begin{tabular}{|c|c|c|c|c|}
\hline & Male & Female & Odds ratio/regression coefficient & $P$ value \\
\hline \multicolumn{5}{|l|}{ Symptoms } \\
\hline Cough (\%) & 72.8 & 51.7 & 4.33 & 0.0015 \\
\hline Phlegm (\%) & 71.2 & 51.7 & 2.68 & 0.025 \\
\hline Shortness of breath (\%) & 32.4 & 44.8 & 1.08 & 0.87 \\
\hline Wheeze (\%) & 49.8 & 55.2 & 1.06 & 0.89 \\
\hline \multicolumn{5}{|l|}{ CT chest findings } \\
\hline Emphysema (\%) & 45.8 & 33.3 & 1.51 & 0.39 \\
\hline Bronchial dilatation (\%) & 22.2 & 16.6 & 1.21 & 0.73 \\
\hline Air trapping $(\%)$ & 29.1 & 22.2 & 2.62 & 0.083 \\
\hline Bronchial wall thickening (\%) & 16.5 & 13.3 & 1.11 & 0.86 \\
\hline \multicolumn{5}{|l|}{ Pulmonary function testing } \\
\hline FEV1/FVC & 76.3 & 78.3 & -1.48 & 0.40 \\
\hline FEV1\% predicted & 91.4 & 97.3 & -8.35 & 0.0086 \\
\hline RV\% predicted & 115.1 & 99.4 & $0.116^{*}$ & 0.0496 \\
\hline TLC\% predicted & 103.5 & 99.8 & 2.57 & 0.42 \\
\hline DLCO $\%$ predicted & 79.9 & 75.5 & 4.35 & 0.19 \\
\hline
\end{tabular}

${ }^{*}$ The regression coefficient for RV\% predicted is in the log scale.

TABLE 3: Clinical characteristics of subjects undergoing bronchoalveolar lavage with alveolar macrophage proteomic analysis.

\begin{tabular}{|c|c|c|c|c|c|}
\hline Gender & HAART & Current smoker & Pack years & Age & Race \\
\hline F & $\mathrm{Y}$ & $\mathrm{N}$ & 1 & 37 & $\mathrm{~W}$ \\
\hline $\mathrm{F}$ & $\mathrm{Y}$ & $\mathrm{Y}$ & 31 & 47 & $\mathrm{~W}$ \\
\hline $\mathrm{F}$ & $\mathrm{Y}$ & $\mathrm{Y}$ & 16 & 48 & B \\
\hline $\mathrm{F}$ & $\mathrm{Y}$ & $\mathrm{Y}$ & 6 & 47 & B \\
\hline $\mathrm{F}$ & $\mathrm{Y}$ & $\mathrm{Y}$ & 11 & 33 & $\mathrm{~W}$ \\
\hline $\mathrm{F}$ & $\mathrm{Y}$ & $\mathrm{Y}$ & 28 & 52 & $\mathrm{~W}$ \\
\hline M & $\mathrm{Y}$ & $\mathrm{N}$ & 1 & 50 & $\mathrm{~W}$ \\
\hline M & $\mathrm{Y}$ & $\mathrm{Y}$ & 36 & 42 & W \\
\hline M & $\mathrm{Y}$ & $\mathrm{Y}$ & 11 & 44 & $\mathrm{~B}$ \\
\hline M & $\mathrm{Y}$ & $\mathrm{Y}$ & 11 & 51 & B \\
\hline M & $\mathrm{Y}$ & $\mathrm{Y}$ & 14 & 34 & $\mathrm{~W}$ \\
\hline M & $\mathrm{Y}$ & $\mathrm{Y}$ & 29 & 45 & $\mathrm{~W}$ \\
\hline
\end{tabular}

not point to COPD as compared to airways disease. It should also be noted that the gender differences we have found may involve pathogenic factors unique to HIV and may not translate to the general population of smokers.

Our results differ from those of Gingo and colleagues who have recently reported lung function and respiratory symptoms among a cohort of HIV-infected subjects [7]. While both the diffusion impairment and respiratory symptoms were prominent in their population, the investigators did not report sex differences. Notably the populations are somewhat different as Gingo and colleagues included both smokers and never-smokers, while our analyses were confined smokers (either current or former). Furthermore, Gingo and coworkers grouped respiratory symptoms in their analyses, possible missing differences among types of symptoms (i.e., airway symptoms versus dyspnea) [7].

A limitation of our study was the disproportionate number of males compared to females, a reflection of the HIV-population in Central Ohio. Future studies, such as the ongoing multicenter Lung HIV study, are prospectively investigating lung function, and respiratory symptoms in over 4000 subjects [8]. Results of this investigation should provide additional insight into potential differences in respiratory outcomes among male and female smokers with HIV.

In addition to symptoms, PFTs, and radiographic difference, we performed alveolar macrophage proteomics in a subgroup of matched females and males to explore potential mechanisms underlying the phenotypic differences in this population. A number of proteins were significantly different between the two sexes. This hypothesis generating approach involves the investigation of the protein content of a biological system $[20,21]$. Since biological phenotypes are largely determined by proteins, differential expression of certain proteins may have mechanistic implications with regard to the gender differences we have identified. These data are limited by 


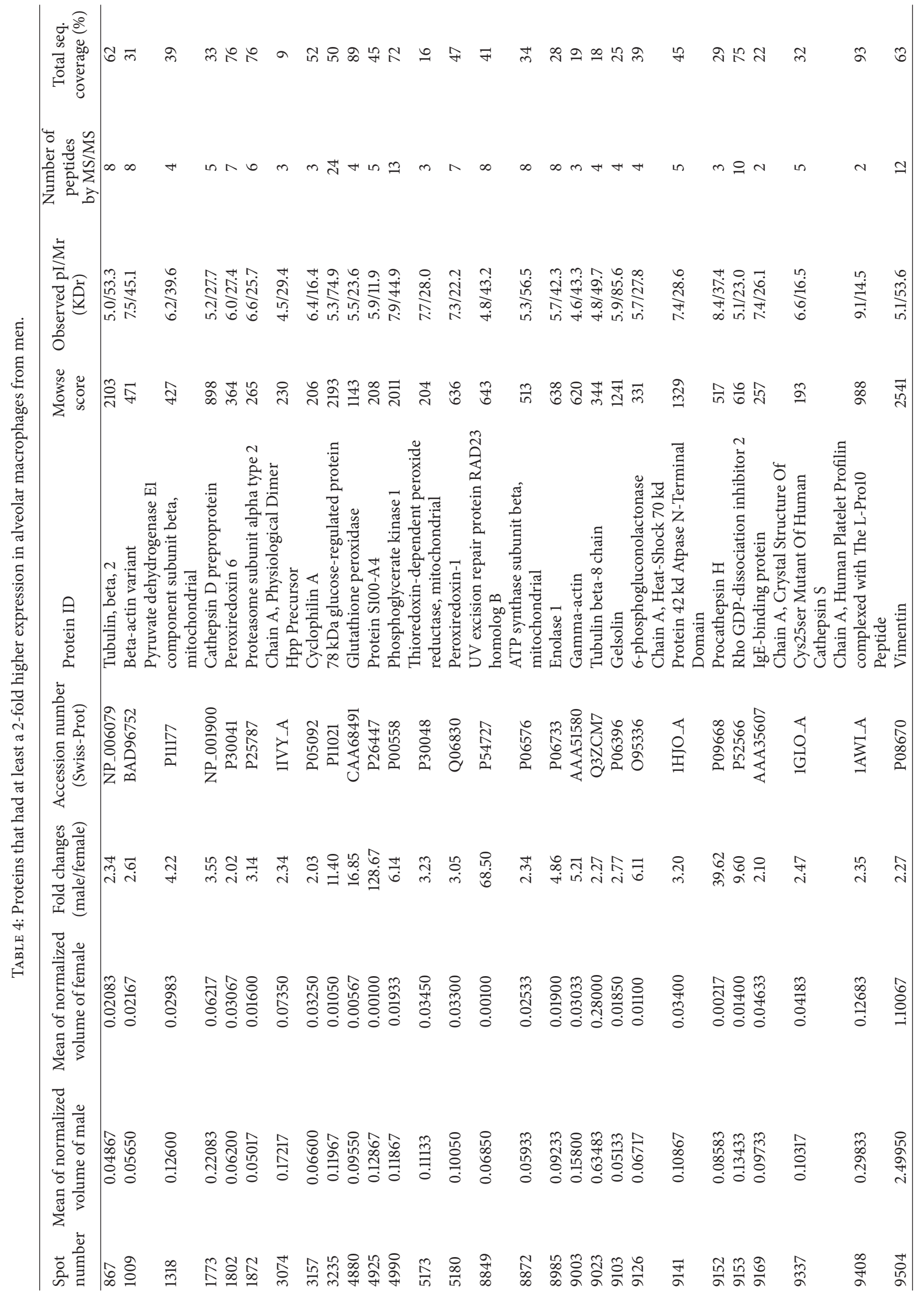




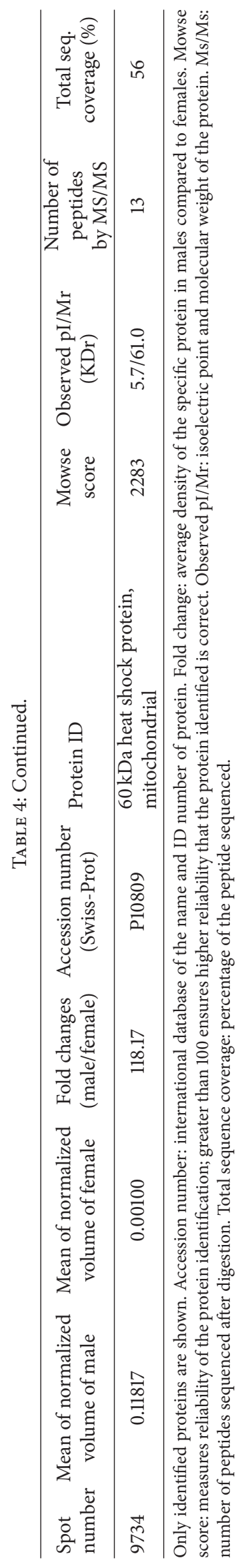




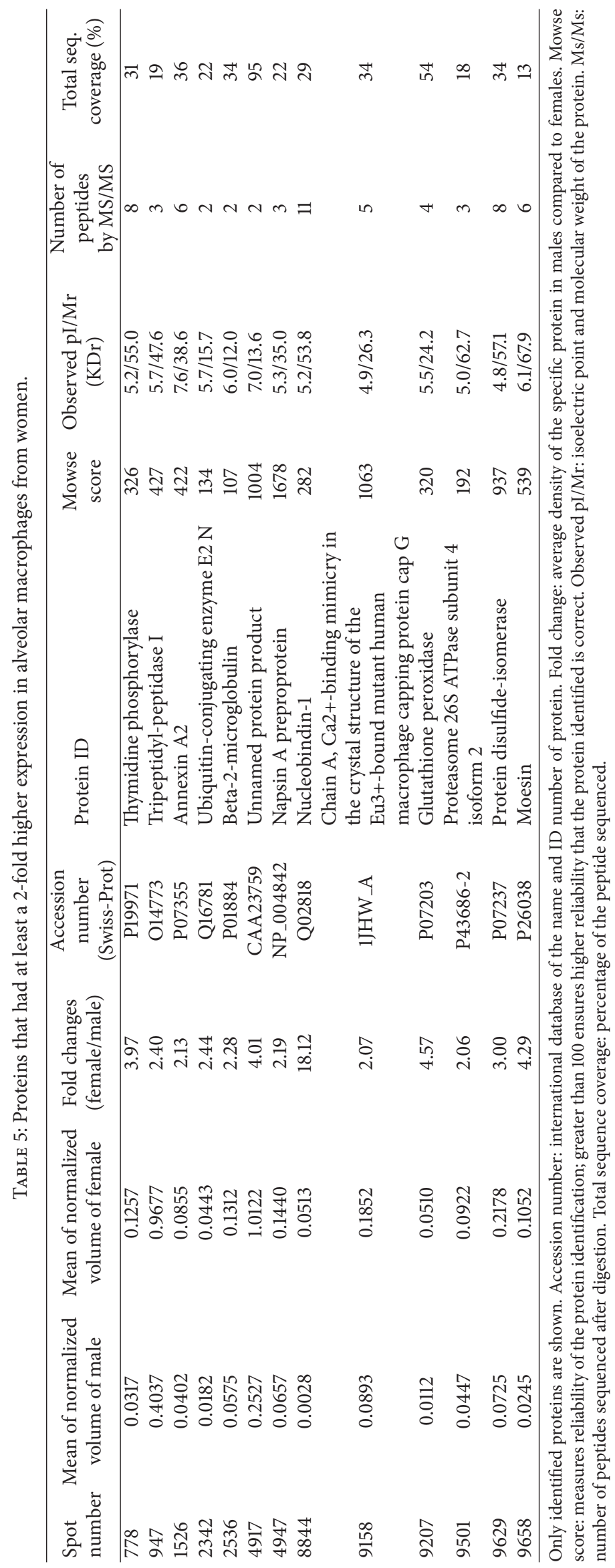


the small number of subjects that were able to have bronchoscopy and alveolar macrophage proteomics. However, in this subset of patients, cathepsin D propreprotein and procathepsin $\mathrm{H}$ (both lysosomal proteins) are expressed at higher levels in the male group. It has been shown that Cathepsin $\mathrm{D}$ contributes to the multiple disease processes including breast cancer [22], Alzheimer disease [23], and HIV [24]. For example, Cathepsin D can modify the conformation of HIV-1 gp120 that in turn directly interacts with the CXCR4 coreceptor and thus enhances HIV infectivity by promoting the entry of HIV into cells [24]. Conceivably, Cathepsin D may contribute to the earlier manifestation of airway symptoms among the male HIV-infected smokers. Interestingly, cathepsin $\mathrm{H}$ has been shown to be upregulated in an IL-13 induced emphysema murine model [25]. Cathepsin $\mathrm{H}$ has also been shown to have a role in surfactant generation [26]. Another study showed that IFN gamma decreased the levels of surfactant protein B and it was thought to be through reduction in cathepsin $\mathrm{H}$ [27]. SP-B may be important in COPD susceptibility and frequency of exacerbations [28]. It is not clear what the cause or consequence of elevated procathepsin $\mathrm{H}$ levels in AM from HIV-infected men, but it is tempting to think it may play a role in the difference in symptoms between men and women. Cleary, these proteomic studies are "hypothesis generating" and follow-up studies are needed to further investigate these observations.

A recent study analyzed gender differences in the proteome of BAL cells in healthy smokers and subjects with COPD. They compared healthy nonsmokers, healthy smokers, and subjects with COPD, while we compared HIVinfected smokers. However, there are some similarities with both studies finding dysregulation of lysosomal proteins in females. In their cohort there was downregulation of cathepsin B in female subjects with COPD as compared with healthy smokers [29].

In conclusion, among a group of relatively young HIVinfected smokers there appear to be differences in the manifestation of respiratory abnormalities, as men seem to develop airway symptoms earlier than women, while both groups have prominent abnormalities in gas exchange. Alveolar macrophage proteomics demonstrate differences in protein expression between the two groups which may provide mechanistic insight. Future study into this phenomenon is warranted as this process may provide insight into COPD pathogenesis in the general population.

\section{Abbreviations}

COPD: Chronic obstructive pulmonary disease

ART: Antiretroviral

HRCT: High resolution computed tomography

AM: Alveolar macrophage

BAL: Bronchoalveolar lavage

FEV1: Forced expiratory volume in one second

RV: $\quad$ Residual volume

DLCO: Diffusing capacity for carbon monoxide

HIV: Human immunodeficiency virus.

\section{Disclosure}

The work was supported in part by the NIH and therefore in accordance with their public access policy is required to be placed in PubMed Central upon acceptance.

\section{Conflict of Interests}

All of the authors report no financial conflict of interests in relation to the completion of this research.

\section{Acknowledgments}

The authors would like to thank Janice Drake and Karen Martin for clinical study coordination and technical support. This work was supported by the following Grants from the NIH: HL083478 and HL090313 and NCRR CTSA award UL1RR025755.

\section{References}

[1] C. D. Mathers and D. Loncar, "Projections of global mortality and burden of disease from 2002 to 2030," PLoS Medicine, vol. 3, no. 11, article e442, 2006.

[2] D. M. Mannino, D. M. Homa, L. J. Akinbami, E. S. Ford, and S. C. Redd, "Chronic obstructive pulmonary disease surveillance-United States, 1971-2000," MMWR Surveillance Summaries, vol. 51, no. 6, pp. 1-16, 2002.

[3] K. Tatsumi, Y. Kasahara, K. Kurosu, N. Tanabe, Y. Takiguchi, and T. Kuriyama, "Clinical phenotypes of COPD: results of a Japanese epidemiological survey," Respirology, vol. 9, no. 3, pp. 331-336, 2004.

[4] P. Carrasco-Garrido, J. de Miguel-Díez, J. Rejas-Gutierrez et al., "Characteristics of chronic obstructive pulmonary disease in Spain from a gender perspective," BMC Pulmonary Medicine, vol. 9, article 2, 2009.

[5] E. K. Silverman, S. T. Weiss, J. M. Drazen et al., "Genderrelated differences in severe, early-onset chronic obstructive pulmonary disease," American Journal of Respiratory and Critical Care Medicine, vol. 162, no. 6, pp. 2152-2158, 2000.

[6] P. T. Diaz, M. A. King, E. R. Pacht et al., "Increased susceptibility to pulmonary emphysema among HIV-seropositive smokers," Annals of Internal Medicine, vol. 132, no. 5, pp. 369-372, 2000.

[7] M. R. Gingo, M. P. George, C. J. Kessinger et al., "Pulmonary function abnormalities in HIV-infected patients during the current antiretroviral therapy era," American Journal of Respiratory and Critical Care Medicine, vol. 182, no. 6, pp. 790-796, 2010.

[8] K. Crothers, B. W. Thompson, K. Burkhardt et al., "HIVassociated lung infections and complications in the era of combination antiretroviral therapy," Proceedings of the American Thoracic Society, vol. 8, no. 3, pp. 275-281, 2011.

[9] H. I. Goldman and M. R. Becklake, "Respiratory function tests; normal values at median altitudes and the prediction of normal results," American Review of Tuberculosis, vol. 79, no. 4, pp. 457467, 1959.

[10] R. O. Crapo, A. H. Morris, and R. M. Gardner, "Reference spirometric values using techniques and equipment that meet ATS recommendations," American Review of Respiratory Disease, vol. 123, no. 6, pp. 659-664, 1981.

[11] A. Miller, J. C. Thornton, and R. Warshaw, "Single breath diffusing capacity in a representative sample of the population of 
Michigan, a large industrial state. Predicted values, lower limits of normal, and frequencies of abnormality by smoking history," American Review of Respiratory Disease, vol. 127, no. 3, pp. 270277, 1983.

[12] M. A. King, D. E.neal, R. S. John, J. Tsai, and P. T.diaz, "Bronchial dilatation in patients with HIV infection: CT assessment and correlation with pulmonary function tests and findings at bronchoalveolar lavage," American Journal of Roentgenology, vol. 168, no. 6, pp. 1535-1540, 1997.

[13] M. Jin, J. M. Opalek, C. B. Marsh, and H. M. Wu, "Proteome comparison of alveolar macrophages with monocytes reveals distinct protein characteristics," American Journal of Respiratory Cell and Molecular Biology, vol. 31, no. 3, pp. 322-329, 2004.

[14] P. K. Smith, R. I. Krohn, and G. T. Hermanson, "Measurement of protein using bicinchoninic acid," Analytical Biochemistry, vol. 150, no. 1, pp. 76-85, 1985.

[15] M. Jin, G. Drwal, T. Bourgeois, J. Saltz, and H. M. Wu, "Distinct proteome features of plasma microparticles," Proteomics, vol. 5, no. 7, pp. 1940-1952, 2005.

[16] H. M. Wu, M. Jin, and C. B. Marsh, "Toward functional proteomics of alveolar macrophages," American Journal of Physiology_Lung Cellular and Molecular Physiology, vol. 288, no. 4, pp. L585-L595, 2005.

[17] M. T. Dransfield, G. R. Washko, M. G. Foreman, R. S. J. Estepar, J. Reilly, and W. C. Bailey, "Gender differences in the severity of CT emphysema in COPD," Chest, vol. 132, no. 2, pp. 464-470, 2007.

[18] T. Laitinen, U. Hodgson, H. Kupiainen et al., "Real-world clinical data identifies gender-related profiles in chronic obstructive pulmonary disease," Journal of Chronic Obstructive Pulmonary Disease, vol. 6, no. 4, pp. 256-262, 2009.

[19] L. Watson, J. M. Vonk, C. G. Löfdahl et al., "Predictors of lung function and its decline in mild to moderate COPD in association with gender: results from the Euroscop study," Respiratory Medicine, vol. 100, no. 4, pp. 746-753, 2006.

[20] J. Hirsch, K. C. Hansen, A. L. Burlingame, and M. A. Matthay, "Proteomics: current techniques and potential applications to lung disease," American Journal of Physiology-Lung Cellular and Molecular Physiology, vol. 287, no. 1, pp. L1-L23, 2004.

[21] S. Hanash, "Disease proteomics," Nature, vol. 422, no. 6928, pp. 226-232, 2003.

[22] V. Vetvicka and M. Fusek, "Procathepsin D as a tumor marker, anti-cancer drug or screening agent," Anti-Cancer Agents in Medicinal Chemistry, vol. 12, no. 2, pp. 172-175, 2012.

[23] M. Schuur, M. A. Ikram, J. C. van Swieten et al., "Cathepsin $\mathrm{D}$ gene and the risk of Alzheimer's disease: a population-based study and meta-analysis," Neurobiology of Aging, vol. 32, no. 9, pp. 1607-1614, 2011.

[24] K. El Messaoudi, L. F. Thiry, C. Liesnard, N. Van Tieghem, A. Bollen, and N. Moguilevsky, "A human milk factor susceptible to cathepsin D inhibitors enhances human immunodeficiency virus type 1 infectivity and allows virus entry into a mammary epithelial cell line," Journal of Virology, vol. 74, no. 2, pp. 10041007, 2000.

[25] T. Zheng, Z. Zhu, Z. Wang et al., "Inducible targeting of IL-13 to the adult lung causes matrix metalloproteinase- and cathepsindependent emphysema," Journal of Clinical Investigation, vol. 106, no. 9, pp. 1081-1093, 2000.

[26] Y. Yayoi, Y. Ohsawa, M. Koike, G. Zhang, E. Kominami, and Y. Uchiyama, "Specific localization of lysosomal aminopeptidases in type II alveolar epithelial cells of the rat lung," Archives of Histology and Cytology, vol. 64, no. 1, pp. 89-97, 2001.
[27] Y. Ito and R. J. Mason, "The effect of interleukin-13 (IL-13) and interferon- $\gamma$ (IFN- $\gamma$ ) on expression of surfactant proteins in adult human alveolar type II cells in vitro," Respiratory Research, vol. 11, article 157, 2010.

[28] M. G. Foreman, D. L. DeMeo, C. P. Hersh et al., "Polymorphic variation in surfactant protein B is associated with COPD exacerbations," European Respiratory Journal, vol. 32, no. 4, pp. 938-944, 2008.

[29] M. Kohler, A. Sandberg, S. Kjellqvist et al., "Gender differences in the bronchoalveolar lavage cell proteome of patients with chronic obstructive pulmonary disease," Journal of Allergy and Clinical Immunology, vol. 131, no. 3, pp. 743-751, 2013. 


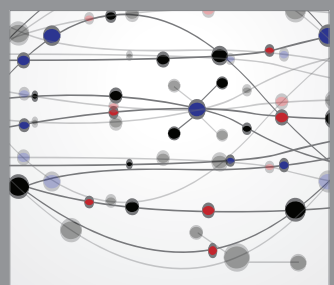

The Scientific World Journal
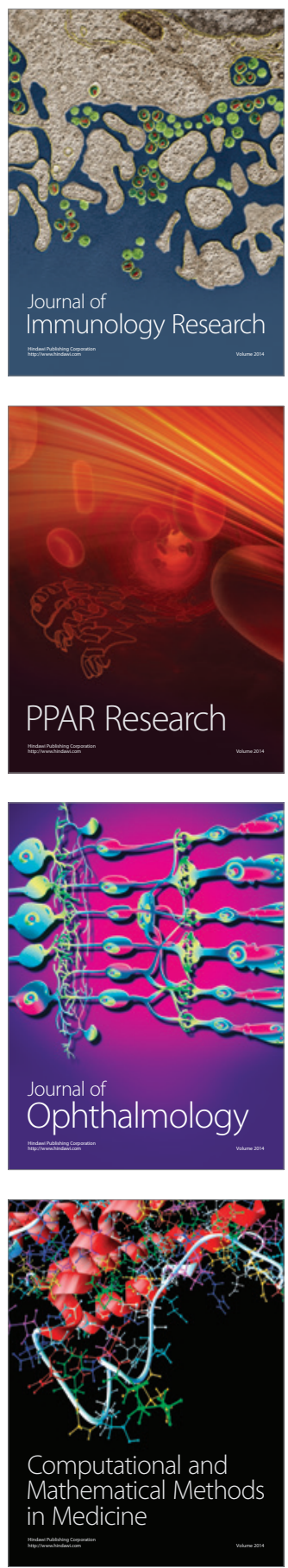

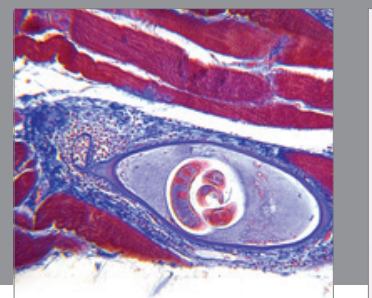

Gastroenterology

Research and Practice
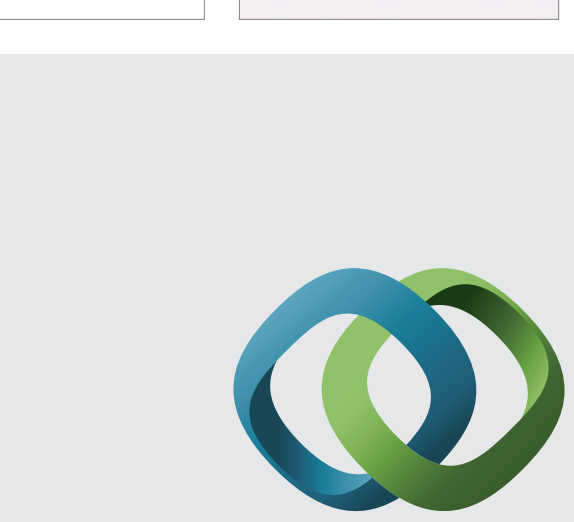

\section{Hindawi}

Submit your manuscripts at

http://www.hindawi.com
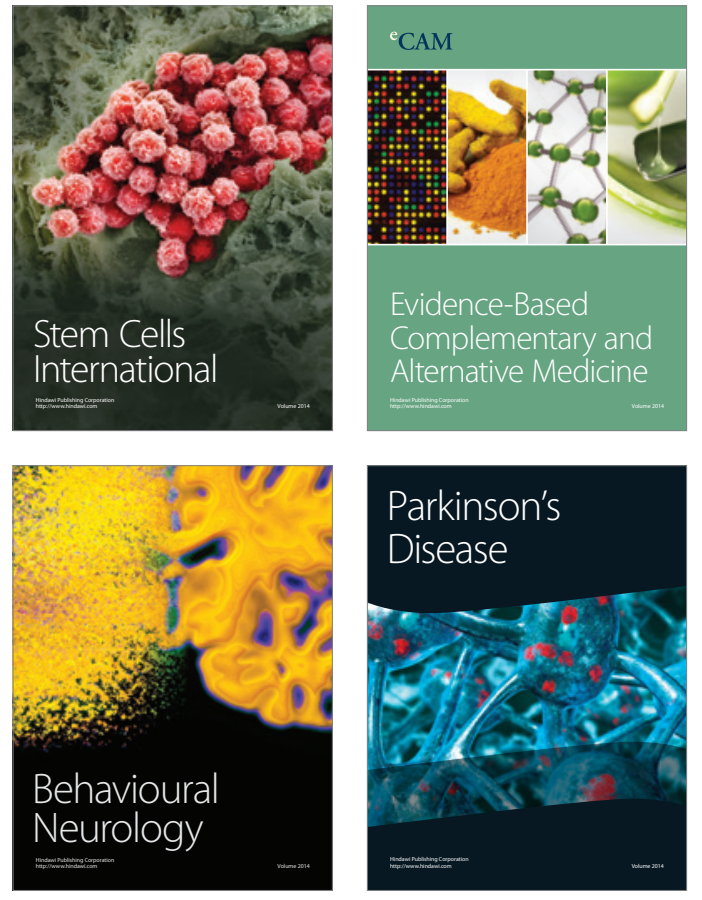
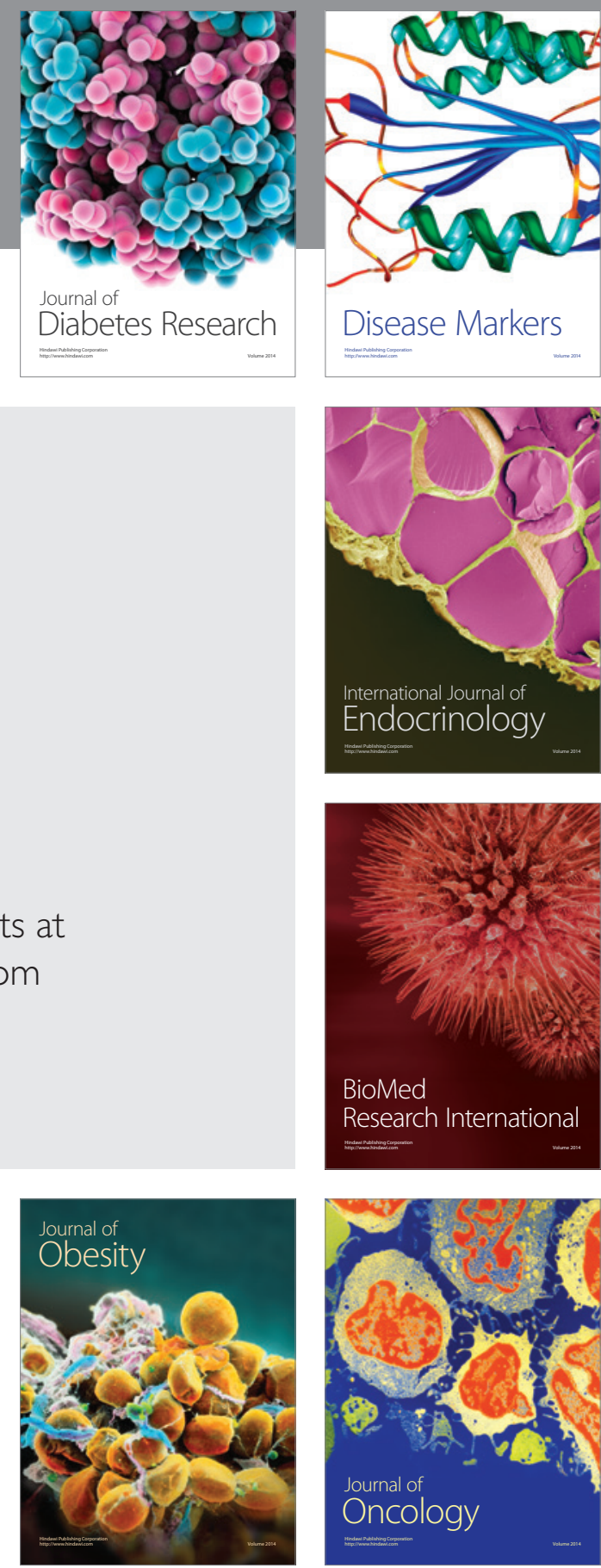

Disease Markers
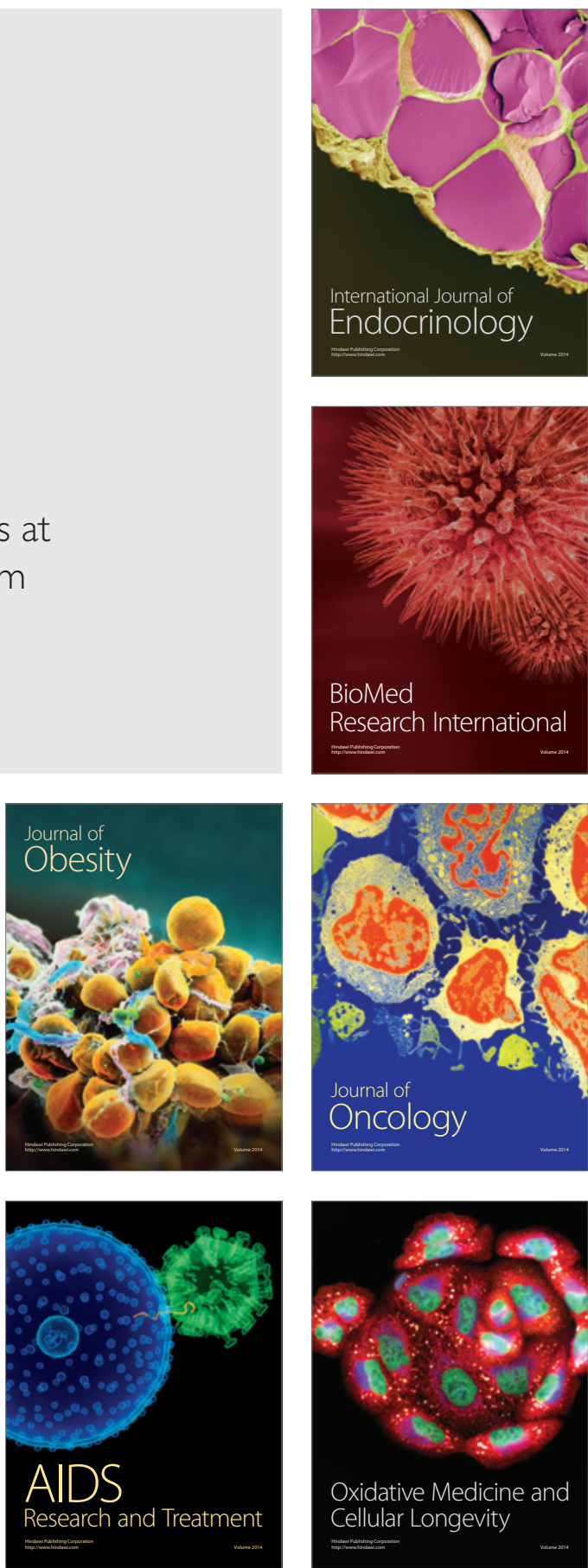